\title{
(6) OPEN ACCESS \\ Socio-environmental correlates of physical activity in patients with chronic obstructive pulmonary disease (COPD)
}

\author{
Ane Arbillaga-Etxarri, ${ }^{1,2,3,4}$ Elena Gimeno-Santos, ${ }^{1,2,3}$ Anael Barberan-Garcia, ${ }^{5,6}$ \\ Marta Benet, ${ }_{10}^{1,2,3}$ Eulàlia Borrell, ${ }_{1}^{7}$ Payam Dadvand, ${ }^{1,2,3}$ Maria Foraster, ${ }_{1}^{8,9}$ \\ Alicia Marín, ${ }^{10}$ Mònica Monteagudo, ${ }^{11,12}$ Robert Rodriguez-Roisin, ${ }^{6}$ \\ Pere Vall-Casas, ${ }^{13}$ Jordi Vilaró, ${ }^{14}$ Judith Garcia-Aymerich, ${ }^{1,2,3}$ \\ on behalf of the Urban Training Study Group
}

- Additional material is published online only. To view please visit the journal online (http://dx.doi.org/10.1136/ thoraxjnl-2016-209209).

For numbered affiliations see end of article.

\section{Correspondence to} Dr Judith Garcia-Aymerich, Barcelona Institute of Global Health (ISGlobal), Barcelona, Spain;

judith.garcia@isglobal.org

Received 19 July 2016 Revised 12 January 2017 Accepted 5 February 2017 Published Online First 1 March 2017
CrossMark

To cite: Arbillaga-Etxarri A, Gimeno-Santos E, BarberanGarcia A, et al. Thorax 2017:72:796-802.

\section{ABSTRACT}

Background Study of the causes of the reduced levels of physical activity in patients with COPD has been scarce and limited to biological factors.

Aim To assess the relationship between novel socioenvironmental factors, namely dog walking, grandparenting, neighbourhood deprivation, residential surrounding greenness and residential proximity to green or blue spaces, and amount and intensity of physical activity in COPD patients.

Methods This cross-sectional study recruited 410 COPD patients from five Catalan municipalities. Dog walking and grandparenting were assessed by questionnaire. Neighbourhood deprivation was assessed using the census Urban Vulnerability Index, residential surrounding greenness by the satellite-derived Normalized Difference Vegetation Index, and residential proximity to green or blue spaces as living within $300 \mathrm{~m}$ of such a space. Physical activity was measured during 1 week by accelerometer to assess time spent on moderate-to-vigorous physical activity (MVPA) and vector magnitude units (VMU) per minute.

Findings Patients were $85 \%$ male, had a mean (SD) age of 69 (9) years, and post-bronchodilator $\mathrm{FEV}_{1}$ of 56 (17) \%pred. After adjusting for age, sex, socio-economic status, dyspnoea, exercise capacity and anxiety in a linear regression model, both dog walking and grandparenting were significantly associated with an increase both in time in MVPA (18 min/day $(p<0.01)$ and $9 \mathrm{~min} /$ day $(p<0.05)$, respectively) and in physical activity intensity (76 VMU/min ( $p=0.05)$ and $59 \mathrm{VMUs} /$ $\min (p<0.05)$, respectively). Neighbourhood deprivation, surrounding greenness and proximity to green or blue spaces were not associated with physical activity.

Conclusions Dog walking and grandparenting are associated with a higher amount and intensity of physical activity in COPD patients.

Trial registration number Pre-results, NCT01897298.

\section{INTRODUCTION}

Patients with COPD are substantially less active than their healthy peers ${ }^{1}$ due to progressive airflow limitation, abnormal gas exchange, skeletal muscle dysfunction, comorbidities and behavioural

\section{Key messages}

What is the key question?

- What is the relationship between socioenvironmental factors, namely dog walking, grandparenting, neighbourhood deprivation, residential surrounding greenness and residential proximity to green or blue spaces, and amount and intensity of physical activity in COPD patients?

What is the bottom line?

- The study shows, for the first time, that interpersonal relationship factors, specifically dog walking and grandparenting, are related to both the amount and intensity of physical activity in COPD patients independent of airflow limitation and other biological or psychological parameters.

\section{Why read on?}

- Understanding the socio-environmental characteristics of COPD patients, including family duties and/or leisure time preferences, is central to tailoring physical activity recommendations in the clinical setting as well as to designing and testing interventions to modify their physical activity behaviour.

changes. ${ }^{2}$ However, maintaining a sufficient amount of physical activity is critical for the patients' prognosis, quality of life and mortality. ${ }^{3}$ Thus, increasing physical activity has been recently included as a relevant health outcome of a wide range of interventions, including pharmacological treatment, ${ }^{4}$ pulmonary rehabilitation ${ }^{5}$ and interventions based on behavioural strategies such as self-monitoring, self-efficacy, motivation, goal setting and feedback. ${ }^{6}$ Of note, only one study so far has shown a sustained long term increase in physical activity, exclusively in a subgroup of patients who were not sufficiently active at baseline.

It has been argued that this absence of effectiveness could be due to lack of knowledge concerning 
the causes of physical activity behaviour. ${ }^{8}$ Remarkably, the number of studies on physical activity determinants in COPD patients is lower than the number of studies assessing interventions to modulate this behaviour. ${ }^{3}$ Moreover, study of physical activity determinants in COPD patients has been limited to individual factors, mostly in the psychological and biological areas. This is in contrast with the commonly accepted socio-ecological models guiding most research on physical activity determinants in the general population and in patients with other chronic diseases. ${ }^{9}$

Socio-ecological models explain physical activity as being affected by psychological, biological and socio-environmental characteristics, and their interactions, both at the individual and population levels. To facilitate the study of socio-environmental characteristics and physical activity, three main dimensions have been described: social inequality, interpersonal relationships and neighbourhood characteristics. ${ }^{10}$ In patients with COPD, only social inequality has been investigated as a potential determinant of physical activity through the application of common measures of socio-economic status (SES), such as educational or occupational categories, and has shown inconsistent associations with physical activity. ${ }^{3}$ However, interpersonal relationships such as walking the dog or grandparenting have not previously been investigated despite the potential of interpersonal relationships to affect physical activity behaviour. ${ }^{10}$ Likewise, neighbourhood characteristics, such as the proximity of parks within walking distance or lower neighbourhood deprivation levels, have been associated with higher levels of physical activity in the general population, ${ }^{11}$ although they have not previously been tested in patients with COPD.

We aimed to assess the relationship of novel socioenvironmental factors (dog walking, grandparenting, neighbourhood deprivation, residential surrounding greenness, and residential proximity to green or blue spaces) with the physical activity level of stable mild-to-very severe patients with COPD from five Mediterranean municipalities.

\section{METHODS}

\section{Study design and population}

This cross-sectional analysis used baseline data from the ongoing multicentre trial 'Effectiveness of an intervention of urban training in patients with chronic obstructive pulmonary disease (COPD): a randomized controlled trial' (NCT01897298). ${ }^{12}$ We first identified all patients with a COPD diagnosis (according to American Thoracic Society and European Respiratory Society (ATS/ERS) criteria) ${ }^{13}$ from 33 primary care centres and five tertiary hospitals of five seaside municipalities in Catalonia: Barcelona, Badalona, Mataró, Viladecans and Gavà (see online supplementary table S1 for their population and area characteristics). Exclusion criteria were: spending $>3$ months/year away from their home address, mental disability, severe psychiatric disease, comorbidity limiting survival to 1 year, or any other severe comorbidity. Between October 2013 and February 2015, all candidate patients were approached in random order within each municipality (Viladecans and Gavà were grouped together because they are adjacent municipalities). Patients were consecutively included until the end of the recruitment period specified for each geographical area based on the primary objective of the study. A total of 410 clinically stable (defined as at least 4 weeks without antibiotics or oral corticosteroids) patients with COPD were enrolled: 189 patients from Barcelona, 30 from Badalona, 73 from Mataró and 119 from Viladecans/Gavà. The study was approved by the Ethics Committees of all participating institutions and written informed consent was obtained from each participant.

\section{Variables and instruments}

All patients answered an interviewer-administered questionnaire about dog ownership (question: 'Do you have a dog at home?'), dog walking (if positive to having a dog, 'Do you walk the dog?'), having grandchildren ('Do you have grandchildren?') and grandparenting (if positive to having grandchildren, 'Do you take care of them or collaborate in their care?'). The questionnaire also included data on education, marital status, working status, occupation, number of people living at home, smoking status, dyspnoea (assessed using the modified Medical Research Council scale (mMRC)), health-related quality of life (assessed using the COPD Assessment Test (CAT)), and anxiety and depression symptoms (assessed using the Hospital Anxiety and Depression scale (HAD)). SES was obtained from questions on employment characteristics, and classified using the National Statistics Socio-economic Classification into six categories (I, professional; II, managerial and technical; IIIN, skilled nonmanual; IIIM, skilled manual; IV, partly skilled; and V, unskilled occupations). Comorbidities were assessed from medical records. Body mass index (BMI) was obtained by physical examination. $\mathrm{FEV}_{1}$ and $\mathrm{FVC}$ before and after bronchodilator use, and distance walked in the 6-min walking test (6MWD) were determined following standardised methodology.

We geocoded patients' addresses to assess individual measures of neighbourhood deprivation, residential surrounding greenness, and residential proximity to green or blue spaces. Neighbourhood deprivation was assessed using the Urban Vulnerability Index ${ }^{14}$ which is a measure of neighbourhood SES at the census tract level (median area of $0.26 \mathrm{~km}^{2}$ ) ranging from 0 (lowest) to 1 (highest level of neighbourhood deprivation).

To measure residential surrounding greenness, we used the Normalized Difference Vegetation Index (NDVI) which is an indicator of green (ie, photosynthetically active) vegetation density based on the difference between visible red and nearinfrared surface reflectance. It was derived from Landsat 8 satellite images with a $30 \mathrm{~m} \times 30 \mathrm{~m}$ spatial resolution during the greenness season in 2014. NDVI has a range from -1 to +1 , with higher values indicating a high density of green vegetation. ${ }^{15}$ Residential surrounding greenness was abstracted as the average NDVI in 100, 300, 500 and $1000 \mathrm{~m}$ buffers from patients' addresses calculated for both network and Euclidean distances. Average NDVI in a network distance of $300 \mathrm{~m}$ was used as the main measure of residential surrounding greenness; the remaining variables were included in sensitivity analyses.

We identified outdoor green (ie, green urban areas, agricultural land and pastures, and forests or country parks) and blue (ie, inland and non-inland water bodies) spaces of $\geq 0.25$ ha. We calculated the network distance between participants' home addresses and the closest green or blue space. Following previous studies ${ }^{16}$ and European Commission recommendations, ${ }^{17}$ we defined residential proximity as living within $300 \mathrm{~m}$ of a green or blue space (equivalent to a 15 min walk).

Physical activity was objectively measured using the Dynaport accelerometer (McRoberts, The Hague, The Netherlands), which has been shown to be a valid tool for measuring physical activity in COPD subjects. ${ }^{18}$ Patients were instructed to wear it attached to the centre of their lower back with an elastic strap for 1 week. A valid physical activity measurement was previously defined as a minimum of 3 days with at least 8 hours of wearing time per day. ${ }^{19}$ The main outcomes of the amount and intensity of physical activity were, respectively, time spent on 
moderate-to-vigorous physical activity (min/day, defined as activity of 3-6 Metabolic Equivalent Tasks (METs)) and vector magnitude units (VMU) per minute. We used three secondary outcomes of physical activity amount: steps per day, walking time $(\mathrm{min} /$ day) and time spent on physical activities (defined as $\geq 1.5$ METs).

\section{Statistical analysis}

Sample size power estimation is detailed in the online supplementary file. To assess the association between socioenvironmental determinants and physical activity, we first tested the bivariate relationship between each socio-environmental determinant (dog walking, grandparenting, neighbourhood deprivation, residential surrounding greenness, and residential proximity to green or blue spaces) and each physical activity variable (time spent on moderate-to-vigorous physical activity, VMU per minute, steps, walking time and time spent on physical activities) using Student's t-test, ANOVA, Kruskal-Wallis, and Wilcoxon rank-sum tests, as appropriate. Second, a multivariable regression model was built for each physical activity variable. As the physical activity variables were normally distributed, we used linear regression. Each model included as exposure variables those socio-environmental characteristics that had exhibited a $\mathrm{p}$ value $<0.2$ in the corresponding bivariate analysis. Age, sex, education, marital status, socio-economic status, working status, smoking history, BMI, dyspnoea, anxiety, depression, $\mathrm{FEV}_{1}, 6 \mathrm{MWD}, \mathrm{FEV}_{1} / \mathrm{FVC}$ ratio, health-related quality of life (CAT score), diabetes, coronary heart disease, hypertension, musculoskeletal disorders, comorbidities that could affect walking, and municipality were tested as potential confounders. Model building combined step-forward and backward algorithms, and covariates were included in the final model if (i) they related to both the exposure and the outcome in bivariable analysis, (ii) they modified $(>10 \%$ change in regression coefficient) the estimates of the remaining variables in the multivariable models, or (iii) there was consistent evidence in the literature of their association with physical activity. Goodness of fit was assessed by means of normality of residuals, heteroscedasticity, linearity, co-linearity, and identification of influential data.

Potential effect modification on the studied associations was evaluated by stratification of the final models according to sex, COPD severity stages (mild-to-moderate and severe-to-very severe), municipality and neighbourhood deprivation (categorised by its median value), and statistical testing of the interaction term. Sensitivity analysis was conducted (i) excluding subjects with extreme values ( $>99$ th percentile) in the accelerometer measures, (ii) using a mixed effects linear model to account for the potential correlation between subjects within a municipality as a random intercept, and (iii) using alternative distance measures to calculate residential surrounding greenness as detailed in the Methods section. Analysis was conducted using a complete case approach in Stata V.14.0 (StataCorp, College Station, Texas, USA).

\section{RESULTS}

Patients were mostly male (85\%) and had a mean (SD) age of 69 (9) years (table 1). According to the ATS/ERS classification, $9 \%$ of patients had mild, 53\% moderate, 31\% severe and 7\% very severe COPD. According to the GOLD ABCD classification, 23\% of patients were in group A, 31\% in B, 13\% in C and $33 \%$ in D. Patients walked a mean of $486(95) \mathrm{m}$ in the 6MWT. Only $12 \%$ and $38 \%$ of patients reported walking the dog or grandparenting, respectively. Half of the patients had green or
Table 1 Socio-demographic and clinical characteristics, socioenvironmental determinants and physical activity in 410 COPD patients

\begin{tabular}{|c|c|}
\hline & $\begin{array}{l}\text { All patients } \\
\mathrm{n}=410^{*}\end{array}$ \\
\hline Sex: male, $n(\%)$ & $349(85)$ \\
\hline Age (years), mean (SD) & $69(8.5)$ \\
\hline Education: primary or less, $\mathrm{n}(\%)$ & $286(70)$ \\
\hline Married or living with partner, $\mathrm{n}(\%)$ & $311(76)$ \\
\hline Low socio-economic status (SES): IV-V, n (\%) & $113(27)$ \\
\hline Working status: active, $\mathrm{n}(\%)$ & $39(9)$ \\
\hline Smoking status: current, n (\%) & $98(24)$ \\
\hline Body mass index (BMI) $\left(\mathrm{kg} / \mathrm{m}^{2}\right)$, mean (SD) & $28.4(4.9)$ \\
\hline Dyspnoea (mMRC grade, $0-4$ ), mean (SD) & $1.2(0.9)$ \\
\hline Post-bronchodilator $\mathrm{FEV}_{1}$ (\% predicted), mean (SD) & $56.3(17.3)$ \\
\hline Post-bronchodilator $\mathrm{FEV}_{1} / \mathrm{FVC}$ ratio, mean (SD) & $55(12)$ \\
\hline $6 \mathrm{MWD}(\mathrm{m})$, mean $(\mathrm{SD})$ & $486(95)$ \\
\hline Health-related quality of life (CAT score, $0-40$ ), mean (SD) & $12(7)$ \\
\hline Anxiety (HAD-A score, 0-21), mean (SD) & $5.2(4)$ \\
\hline Depression (HAD-D score, 0-21), mean (SD) & $3.5(3.3)$ \\
\hline Diabetes mellitus, n (\%) & $114(28)$ \\
\hline Coronary heart disease, $\mathrm{n}(\%)$ & $37(9)$ \\
\hline Hypertension, $\mathrm{n}(\%)$ & $203(51)$ \\
\hline Musculoskeletal disease, n (\%) & $155(39)$ \\
\hline Dog ownership, n (\%) & $75(18)$ \\
\hline Dog walking, n (\%) & $49(12)$ \\
\hline Having grandchildren, $\mathrm{n}(\%)$ & $302(73)$ \\
\hline Grandparenting, n (\%) & $154(38)$ \\
\hline $\begin{array}{l}\text { Neighbourhood deprivation (UVI score, } 0 \text { (low)-1 (high)), } \\
\text { mean (SD) }\end{array}$ & $0.64(0.17)$ \\
\hline $\begin{array}{l}\text { Residential surrounding greenness (NDVI, } 0 \text { (low)-1 (high)), } \\
\text { mean (SD) }\end{array}$ & $0.19(0.05)$ \\
\hline Residential proximity to green or blue spaces, n (\%) & $217(53)$ \\
\hline Minimal distance to green or blue spaces $(\mathrm{m})$, mean (SD) & $297(177)$ \\
\hline Steps (number/day), mean (SD) & $7480(4070)$ \\
\hline Walking time (min/day), mean (SD) & $86(42)$ \\
\hline Time in any physical activity (min/day), mean (SD) & $169(71)$ \\
\hline $\begin{array}{l}\text { Time in moderate-to-vigorous physical activity (min/day), } \\
\text { mean (SD) }\end{array}$ & $105(49)$ \\
\hline VMU/min, mean (SD) & 464 (304) \\
\hline
\end{tabular}

blue spaces within $300 \mathrm{~m}$ of their homes. All patients fulfilled the criterion of wearing time per day (median wearing days 7 , range $3-7$; median recording time 14.9 hours, range $11.1-15$ of 15 hours maximum from 7:00 to 22:00). Patients spent a mean of almost 3 hours/day on physical activity and half of this activity was at least of moderate intensity (table 1).

Figure 1 shows that dog walking and grandparenting were significantly associated with both higher amount and higher intensity of physical activity. However, neighbourhood deprivation, residential surrounding greenness, or residential proximity to green or blue spaces were not related to physical activity parameters. Online supplementary tables S2 and S3 show the bivariate associations between potential confounders and both exposures and outcomes. After adjusting for age, sex, SES, 

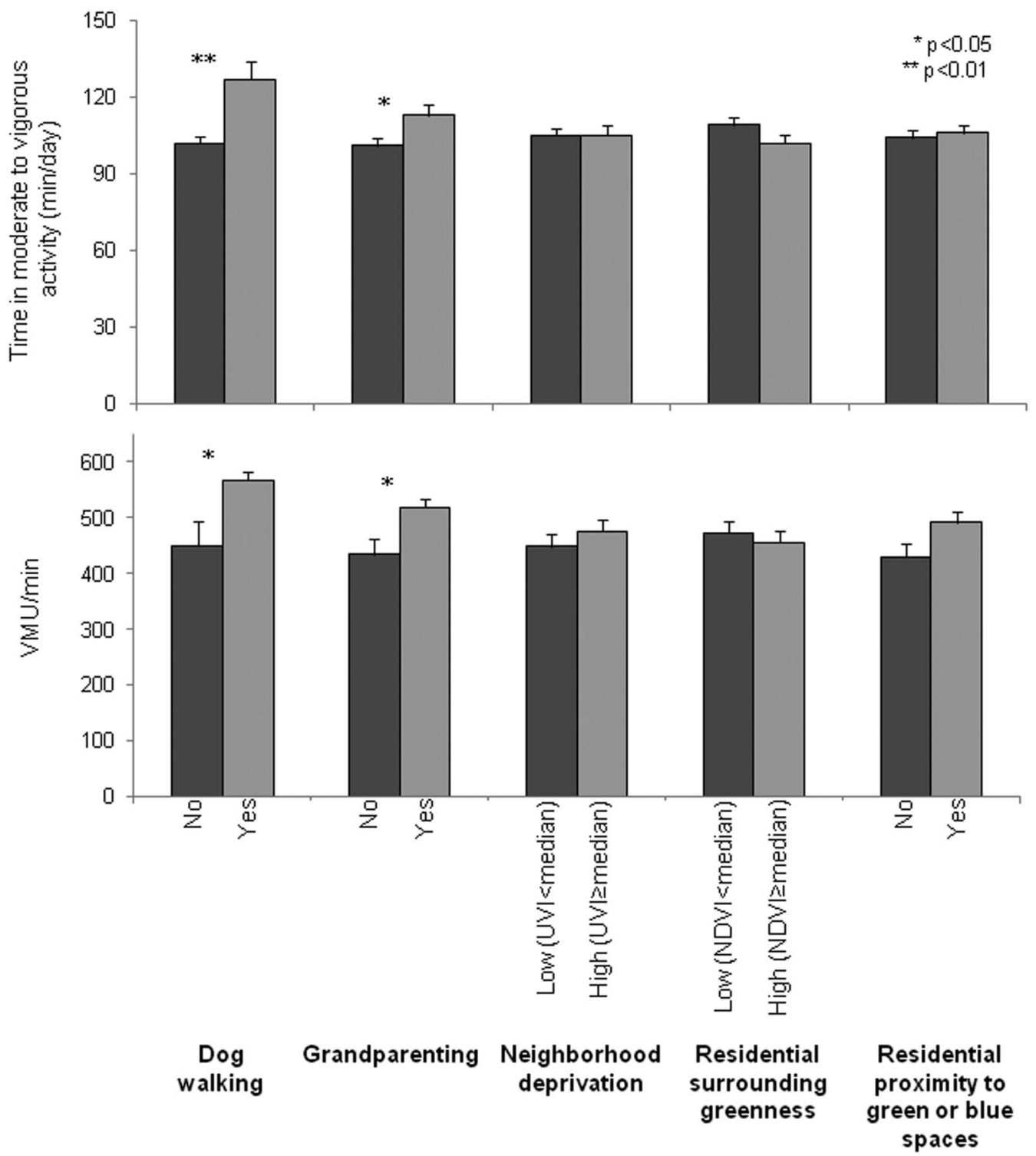

Figure 1 Distribution of amount (time in moderate-to-vigorous activity) and intensity (VMU/min) of physical activity according to socioenvironmental characteristics in COPD patients. NDVI, Normalized Difference Vegetation Index; UVI, Urban Vulnerability Index; VMU, vector magnitude units. Bars represent mean and SE.

smoking, dyspnoea, exercise capacity and anxiety, dog walking was significantly associated with an increase in moderate-tovigorous physical activity of $18 \mathrm{~min} /$ day $(\mathrm{p}<0.01)$, and an increase in physical activity intensity of $76 \mathrm{VMUs} / \mathrm{min}(\mathrm{p}=0.05)$, as compared to not walking a dog (table 2). Grandparenting was also related to both higher amount and higher intensity of physical activity after adjusting for potential confounders (table 2). Very similar associations were obtained for steps and times engaged in walking and physical activity of any intensity (see online supplementary table S4). There was no interaction between dog walking and grandparenting in their association with physical activity amount or intensity. Goodness of fit tests did not reveal any abnormality.

After stratification by sex, the association between grandparenting and time in moderate-to-vigorous physical activity was observed only in men ( $\mathrm{p}$-for-interaction $=0.02$ ) (see tables 3 and online supplementary table S5). No differences were observed after stratification according to COPD severity stage (mild-to-moderate and severe-to-very severe), municipality and neighbourhood deprivation. Sensitivity analysis excluding subjects with extreme physical activity values (see online supplementary table S6) or using a mixed effects linear model (see online supplementary table S7) showed very similar estimates. Alternative buffers to calculate residential surrounding greenness did not provide additional information (see online supplementary figure S1).

\section{DISCUSSION}

We assessed the relationship between socio-environmental factors and the physical activity level of clinically stable mild-to-very severe patients with COPD and found, for the first time, that dog walking and grandparenting are both associated with a higher amount and intensity of physical activity in COPD patients. However, the characteristics of green or blue spaces surrounding patients' homes were not associated with physical activity practice.

These results are consistent with previous research showing that dog walking is associated with higher physical activity in 
Table 2 Adjusted association* between socio-environmental characteristics and physical activity amount and intensity in COPD patients

\begin{tabular}{|c|c|c|c|c|}
\hline & \multicolumn{2}{|c|}{$\begin{array}{l}\text { Time in physical activity of } \\
\text { moderate-to-vigorous intensity (min/day) }\end{array}$} & \multicolumn{2}{|l|}{$\mathrm{VMU} / \mathrm{min}$} \\
\hline & $\boldsymbol{\beta}(95 \% \mathrm{Cl})$ & p Value & $\boldsymbol{\beta}(95 \% \mathrm{CI})$ & p Value \\
\hline Dog walking & 19 (7 to 32$)$ & $<0.01$ & $88(13-163)$ & 0.02 \\
\hline Grandparenting & $8(-0.3$ to 17$)$ & 0.06 & $55(4-105)$ & 0.03 \\
\hline Age (years) & $-0.7(-1.3$ to -0.2$)$ & 0.01 & $-3.6(-7$ to -0.3$)$ & 0.03 \\
\hline Sex: male & $3(-9$ to 15$)$ & 0.62 & $24(-49$ to 97$)$ & 0.51 \\
\hline Low SES: IV, V & 10 (1 to 20$)$ & 0.03 & 86 (30 to 141$)$ & $<0.01$ \\
\hline Active smoking & $-20(-30$ to -10$)$ & $<0.01$ & $-148(-207$ to -89$)$ & $<0.01$ \\
\hline Dyspnoea (mMRC, 0-4) & $-11(-16$ to -5$)$ & $<0.01$ & $-59(-90$ to -28$)$ & $<0.01$ \\
\hline 6MWD (m) & $0.1(0.1-0.2)$ & $<0.01$ & 1 (0.8 to 1.5$)$ & $<0.01$ \\
\hline Anxiety (HAD-A score, 0-21) & $1.1(0.01$ to 2.2$)$ & 0.04 & $3(-4$ to 9$)$ & 0.40 \\
\hline
\end{tabular}

both older healthy adults and patients with type 2 diabetes. $^{20-22}$ Whether this association may be extrapolated into an effective intervention to increase physical activity in patients with COPD is still a matter of debate. A recent review highlighted that dog walking constitutes a specific behaviour different from other physical activities or even other types of walking because it has its specific barriers and facilitators and takes place in a specific individual, mental, physical, social and environmental context. For example, concerns about dogs coming into contact with children or other park users, crowded places, and large or uncontrolled dogs have been identified as barriers to dog walking. On the other hand, accessible appropriate public open spaces for dogs or neighbourhood walkability act as facilitators for this activity. ${ }^{20}$ Therefore, before interventions are designed for improving physical activity by means of dogs, research is needed to understand the specific characteristics of patients with COPD who walk their dogs and the factors influencing dog walking behaviour in this population. ${ }^{23}$

The patients with COPD who reported grandparenting exhibited higher levels of physical activity amount and intensity. Indeed, previous studies had already shown that grandparenting had significant benefits for grandparents' physical and mental health, ${ }^{24-26}$ but this had never been tested in chronically ill patients, such as those with COPD. Interestingly, patients with COPD have reported that caring for and playing with grandchildren is a motivator to undertake a pulmonary rehabilitation programme. ${ }^{27}$ Thus, grandparenting may represent an excellent opportunity for promoting physical activity in this aging population. Our finding that the benefits for physical activity may be restricted to grandfathers needs a cautious interpretation because of a lack of statistical power in the female group (15\% of the sample). We hypothesise that grandmothers caring for grandchildren may carry out domestic tasks, like cooking or feeding the grandchildren, which do not require intense physical activity, while grandfathers may spend more time outdoors, picking grandchildren up, or playing with them. Previous studies have reported different effects of grandparenting depending on sex. ${ }^{24} 26$

We did not find any association between residential surrounding greenness and residential proximity to green or blue spaces and physical activity in our patients with COPD. In the general adult population, the proximity and number of green spaces around the home has been related to higher levels of physical activity, ${ }^{11}$ but this association has not been shown to be consistent across studies. ${ }^{28}$ In fact, a recent study carried out in
Barcelona showed that perceived proximity to green spaces, but not objective proximity, was associated with higher physical activity. ${ }^{29}$ It has been reported that the relationship between the built environment and physical activity characteristics is not equal for the entire population but modulated by sex, age, SES or working status. ${ }^{30}$ We hypothesise that, in subjects with limited exercise capacity like patients with COPD, the ability of a favourable built environment to stimulate physical activity could be lower than in healthy subjects. This is supported by a recent study showing that the aesthetics of the built environment were related to physical activity levels only in healthy subjects but not in those with chronic disease. ${ }^{32}$ Therefore, despite the increasing evidence of the association between the built environment and physical activity in the general adult population, qualitative and quantitative research is required to determine how the built environment affects behaviour in patients with COPD or other chronic diseases before considering the use of green or blue spaces to promote their physical activity.

Neighbourhood deprivation was not associated with physical activity in our study, which could be partially explained by the small variability in the urban vulnerability score in the five included municipalities. However, low SES was associated with a higher amount and greater intensity of physical activity, at variance with previous studies in patients with COPD from Barcelona that reported higher physical activity in the higher SES categories. ${ }^{3}$ Such a difference could be attributed to the fact that the current study included patients from middle-sized municipalities with population densities and historical urban backgrounds different from that of Barcelona, which could result in different social behaviour. ${ }^{33}$

The results of this study provide novel and original information to help enhance physical activity for patients with COPD in the clinical setting, highlighting the potential of interpersonal relationships as determinants of behaviour. Questioning the patients about their family duties and/or leisure time preferences can help professionals customise physical activity recommendations. In patients with diabetes for example, the necessity of encouraging dog walking or identifying other activities that promote a regular commitment to undertake physical activity has been recognized. ${ }^{21}$ Our results support the advice concerning dog walking, which can be used in patients who already own a dog but otherwise needs a deep understanding of patient preferences and fears. Grandparenting and, in general, encouraging grandparents to have an active role in family 


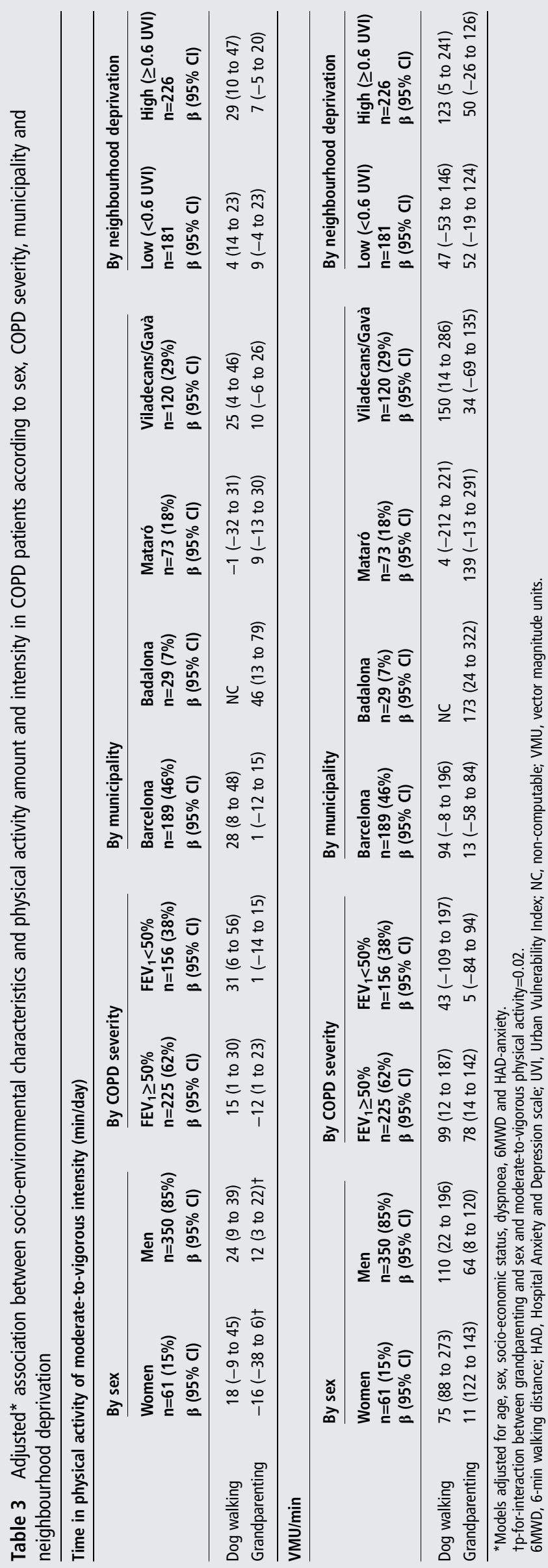

responsibilities, may be an effective way to increase their physical activity. Current findings also indicate that that clinical COPD recommendations should include social and environmental factors as part of the basic medical assessment. ${ }^{2}$ Finally, although our findings indicate that greenness or proximity to green or blue spaces is not associated with patients' physical activity, these spaces could be used as part of a complementary strategy to promote physical activity in patients with COPD.

The strengths of this study are the novelty of the approach, including individual and community socio-environmental variables, the use of an objective measure of physical activity that prevents misclassification at the individual level, and the wide distribution of patients across COPD severity grades. Moreover, recruitment of patients from both primary and tertiary care centres, adds external validity to our study, as demonstrated by the fact that our patients exhibit less disease severity than that observed in previous randomised trials and similar to that from other primary care COPD cohorts. ${ }^{34}$ The recruitment from several municipalities with diverse socio-environmental conditions also increases generalisability, although limited to the context of Euro-Mediterranean cities.

A limitation is the cross-sectional design of the study, so the directionality of the associations cannot be established. However, we consider it highly unlikely that patients with COPD at that age change their family situation or move as a result of their physical activity levels. The lack of other measurements of physical environment, such as the quality of green spaces, street walkability, sport facilities, connectivity, car traffic, noise and air pollution, may have limited our ability to understand the neighbourhood physical activity determinants in patients with COPD. Indeed, these outcomes need to be addressed in future investigations. Finally, as alluded to above, the results of this study may not be extrapolated to cities with very different cultural or climatic conditions, so more studies targeting different COPD populations are needed.

In conclusion, dog walking and grandparenting are associated with a higher amount and intensity of physical activity in patients with COPD. The social characteristics of patients with COPD should be considered to promote physical activity both at the clinical level and in future research.

\section{Author affiliations}

${ }^{1}$ Barcelona Institute of Global Health (ISGlobal), Barcelona, Spain

2Universitat Pompeu Fabra (UPF), Barcelona, Spain

${ }^{3}$ CIBER Epidemiología y Salud Pública (CIBERESP), Barcelona, Spain

${ }^{4}$ Physical Activity and Sports Sciences, Faculty of Psychology and Education,

University of Deusto, Donostia-San Sebastián, Spain

${ }^{5}$ Respiratory Clinic Institute, Hospital Clinic of Barcelona, Barcelona, Spain

${ }^{6}$ Institut d'Investigacions Biomèdiques August Pi i Sunyer (IDIBAPS)-Hospital Clínic, University of Barcelona, Barcelona, Spain

${ }^{7}$ Sant Roc Primary Care Center, Badalona, Spain

${ }^{8}$ Swiss Tropical and Public Health Institute, University of Basel, Basel, Switzerland

${ }^{9}$ University of Basel, Basel, Switzerland

${ }^{10}$ Pneumology Department, Hospital Germans Trias i Pujol, CIBER Respiratory Diseases (CIBERES), Badalona, Spain

${ }^{11}$ Institut Universitari d'Investigació en Atenció Primària Jordi Gol (IDIAP Jordi Gol), Barcelona, Spain

${ }^{12}$ Universitat Autònoma de Barcelona, Bellaterra (Cerdanyola del Vallès), Spain

${ }^{13}$ Universitat Internacional de Catalunya (UIC), Barcelona, Spain

${ }^{14}$ FCS Blanquerna, Research Group on Health, Physical Activity and Sport (SAFE), Ramon Llull University, Barcelona, Spain

Acknowledgements The authors thank Jaume Torrent, Anna Delgado and Marta Cirach from Barcelona Institute of Global Health (ISGlobal), Barcelona, for their technical support and contribution to the conduct of the study.

Collaborators This study was performed on behalf of the Urban Training Study Group: Barcelona Institute of Global Health (ISGlobal), Barcelona: Ane Arbillaga-Etxarri, Marta Benet, Anna Delgado, Judith Garcia-Aymerich, Elena 
Gimeno-Santos, Jaume Torrent-Pallicer; FCS Blanquerna, Universitat Ramon Llull, Barcelona: Jordi Vilaró; Servei de Pneumologia, Hospital Clínic de Barcelona, Barcelona: Anael Barberan-Garcia; Universitat de Barcelona: Robert Rodriguez-Roisín; Hospital del Mar, Institut Hospital del Mar d'Investigacions Mèdiques (IMIM), Barcelona: Eva Balcells, Diego A Rodríguez; Hospital Universitari Germans Trias i Pujol, Badalona: Alicia Marín; Hospital de Mataró, Consorci Sanitari del Maresme, Mataró: Pilar Ortega; Hospital de Viladecans, Viladecans: Nuria Celorrio; Institut Universitari d'Investigació en Atenció Primària Jordi Gol (IDIAP Jordi Gol): Mónica Monteagudo, Nuria Montellà, Laura Muñoz, Pere Toran; Centre d'Atenció Primària Viladecans 2, Institut Català de la Salut, Viladecans: Pere Simonet; Centre d'Atenció Primària Passeig de Sant Joan, Institut Català de la Salut, Barcelona: Carme Jané, Carlos Martín-Cantera; Centre d'Atenció Primària Sant Roc, Institut Català de la Salut, Badalona: Eulàlia Borrell; Universitat Internacional de Catalunya (UIC), Barcelona: Pere Vall-Casas.

Contributors $A A E$ and JGA wrote the initial draft. $A A E, M B$ and JGA had full access to the data and carried out statistical analysis. $A A E, A B G, E B, A M$ and $M M$ contributed to data collection and coordination. All authors (i) provided substantial contributions to the conception or design of the work, or the acquisition, analysis or interpretation of data for the work, (ii) revised the manuscript for important intellectual content, (iii) approved the final version, and (iv) agreed to be accountable for all aspects of the work.

Funding The study was funded by grants from Fondo de Investigación Sanitaria, Instituto de Salud Carlos III (ISCIII), Spain (PI11/01283 and PI14/0419), Sociedad Española de Neumología y Cirugía Torácica (SEPAR) (147/2011 and 201/2011), Societat Catalana de Pneumologia (Ajuts al millor projecte en fisioterà pia respiratòria 2013), integrated into Plan Estatal I+D+I 2013-2016 and co-funded by ISCIII-Subdirección General de Evaluación y Fomento de la Investigación and Fondo Europeo de Desarrollo Regional (FEDER). Anael Barberan-Garcia had personal funding from Agaur 2014-SGR-661, Catalan Government. Payam Dadvand is funded by a Ramón y Cajal fellowship (RYC-2012-10995) awarded by the Spanish Ministry of Economy and Competitiveness.

Competing interests RRR reports receipt of grants/research support from Almirall (not related to this study), lectured for Almirall, AstraZeneca, Boehringer Ingelheim, Ferrer, Menarini, Novartis, Takeda and TEVA, and consulted with AstraZeneca, Boehringer Ingelheim, Pearl, Takeda and TEVA. AAE, EGS, ABG, MB, LB, MF, PD, AM, MM, PVC, JV and JGA have nothing to disclose. There are no patents, products in development or marketed products to declare.

Patient consent Obtained.

Ethics approval Comitè Étic d'Investigació Clínica Hospital Germans Trias i Pujol; Comitè d'Investigació Hospital Clínic; Comitè Étic d'Investigació Clínica IDIAP Jordi Gol; Comitè Étic d'Investigació Clínica Hospital de Mataró; Comitè Étic d'Investigació Clínica Parc de Salut MAR; Comitè Étic d'Investigació Clínica Hospital Universitari de Bellvitge.

Provenance and peer review Not commissioned; externally peer reviewed.

Open Access This is an Open Access article distributed in accordance with the Creative Commons Attribution Non Commercial (CC BY-NC 4.0) license, which permits others to distribute, remix, adapt, build upon this work non-commercially, and license their derivative works on different terms, provided the original work is properly cited and the use is non-commercial. See: http://creativecommons.org/ licenses/by-nc/4.0/

\section{REFERENCES}

1 Vorrink SNW, Kort HSM, Troosters T, et al. Level of daily physical activity in individuals with COPD compared with healthy controls. Respir Res 2011;12:33.

2 Vestbo J, Hurd SS, Agustí AG, et al. Global strategy for the diagnosis, management, and prevention of chronic obstructive pulmonary disease: GOLD executive summary. Am J Respir Crit Care Med 2013;187:347-65.

3 Gimeno-Santos E, Frei A, Steurer-Stey C, et al. Determinants and outcomes of physical activity in patients with COPD: a systematic review. Thorax 2014;69:731-9.

4 Watz H, Krippner F, Kirsten A, et al. Indacaterol improves lung hyperinflation and physical activity in patients with moderate chronic obstructive pulmonary disease--a randomized, multicenter, double-blind, placebo-controlled study. BMC Pulm Med 2014; 14:158

5 Spruit MA, Pitta F, McAuley E, et al. Pulmonary rehabilitation and physical activity in patients with chronic obstructive pulmonary disease. Am J Respir Crit Care Med 2015;192:924-33.

6 Leidy NK, Kimel M, Ajagbe L, et al. Designing trials of behavioral interventions to increase physical activity in patients with COPD: insights from the chronic disease literature. Respir Med 2014;108:472-81.

7 Altenburg WA, ten Hacken NH, Bossenbroek L, et al. Short- and long-term effects of a physical activity counselling programme in COPD: a randomized controlled trial. Respir Med 2015;109:112-21.

8 Garcia-Aymerich J. Research needs on physical activity and COPD: bridging the gap between knowledge and behaviour. BRN Rev 2015;1:92-104.
9 Bauman $A E$, Reis RS, Sallis JF, et al. Correlates of physical activity: why are some people physically active and others not? Lancet 2012;380:258-71.

10 McNeill LH, Kreuter MW, Subramanian SV. Social environment and physical activity: a review of concepts and evidence. Soc Sci Med 2006;63:1011-22.

11 Sallis JF, Cerin E, Conway TL, et al. Physical activity in relation to urban environments in 14 cities worldwide: a cross-sectional study. Lancet 2016;387:2207-17

12 Arbillaga-Etxarri A, Torrent-Pallicer J, Gimeno-Santos E, et al. Validation of walking trails for the Urban Training ${ }^{\mathrm{TM}}$ of chronic obstructive pulmonary disease patients. PLOS ONE 2016;11:e0146705.

13 Celli BR, MacNee W, Agusti A, et al. Standards for the diagnosis and treatment of patients with COPD: a summary of the ATS/ERS position paper. Eur Respir J 2004:23:932-46.

14 Atlas de la Vulnerabilidad Urbana. Ministerio de Fomeno. Gobierno de España. http://www.fomento.gob.es/MFOM/LANG_CASTELLANO/DIRECCIONES_ GENERALES/ARQ_VIVIENDA/SUELO_Y_POLITICAS/OBSERVATORIO/Atlas_ Vulnerabilidad Urbana/ (accessed 13 May 2013).

15 Weier J, Herring D. 2011. Measuring Vegetation (NDVI \& EVI). http:// earthobservatory.nasa.gov/Features/MeasuringVegetation/ (accessed 13 May 2013).

16 Annerstedt M, Ostergren PO, Björk J, et al. Green qualities in the neighbourhood and mental health-results from a longitudinal cohort study in Southern Sweden. BMC Public Health 2012;12:337.

17 European Commission, Expert Group on the Urban Environment. Towards a Local Sustainability Profile-European Common Indicators. Luxembourg: Office for Official Publications of the European Communities, 2001

18 Rabinovich RA, Louvaris Z, Raste $Y$, et al. Validity of physical activity monitors during daily life in patients with COPD. Eur Respir J 2013;42:1205-15.

19 Demeyer H, Burtin C, Van Remoortel H, et al. Standardizing the analysis of physical activity in patients with COPD following a pulmonary rehabilitation program. Chest 2014; 146:318-27

20 Westgarth C, Christley RM, Christian HE. How might we increase physical activity through dog walking?: a comprehensive review of dog walking correlates. Int J Behav Nutr Phys Act 2014;11:83.

21 Peel E, Douglas M, Parry O, et al. Type 2 diabetes and dog walking: patients longitudinal perspectives about implementing and sustaining physical activity. Br J Gen Pract 2010;60:570-7.

22 Curl AL, Bibbo J, Johnson RA. Dog walking, the human-animal bond and older adults' physical health. Gerontologist. Published Online First: 21 Mar 2016. doi: https://doi.org/10.1093/geront/gnw051

23 Christian HE, Westgarth C, Bauman A, et al. Dog ownership and physical activity: a review of the evidence. J Phys Act Health 2013;10:750-9.

24 Di Gessa G, Glaser K, Tinker A. The impact of caring for grandchildren on the health of grandparents in Europe: a lifecourse approach. Soc Sci Med 2016;152:166-75.

25 Tsai F-J, Motamed S, Rougemont A. The protective effect of taking care of grandchildren on elders' mental health? Associations between changing patterns of intergenerational exchanges and the reduction of elders' loneliness and depression between 1993 and 2007 in Taiwan. BMC Public Health 2013;13:567.

26 Grundy EM, Albala C, Allen E, et al. Grandparenting and psychosocial health among older Chileans: a longitudinal analysis. Aging Ment Health 2012;16:1047-57.

27 Harris D, Hayter M, Allender S. Improving the uptake of pulmonary rehabilitation in patients with COPD: qualitative study of experiences and attitudes. $\mathrm{Br} / \mathrm{Gen}$ Pract 2008;58:703-10

28 Van Holle V, Deforche B, Van Cauwenberg J, et al. Relationship between the physical environment and different domains of physical activity in European adults: a systematic review. BMC Public Health 2012;12:807.

29 Dadvand $P$, Bartoll X, Basagaña $X$, et al. Green spaces and general health: roles of mental health status, social support, and physical activity. Environ Int 2016;91:161-7.

30 Kaczynski AT, Besenyi GM, Stanis SAW, et al. Are park proximity and park features related to park use and park-based physical activity among adults? Variations by multiple socio-demographic characteristics. Int J Behav Nutr Phys Act 2014:11:146.

31 Van Cauwenberg J, Cerin E, Timperio A, et al. Park proximity, quality and recreational physical activity among mid-older aged adults: moderating effects of individual factors and area of residence. Int J Behav Nutr Phys Act 2015;12:1-8.

32 Barnett A, Cerin E, Zhang CJP, et al. Associations between the neighbourhood environment characteristics and physical activity in older adults with specific types of chronic conditions: the ALECS cross-sectional study. Int I Behav Nutr Phys Act 2016;13:53.

33 Pla territorial metropolità de Barcelona. Departament de Territori i Sostenibilitat. http://territori.gencat.cat/ca/01_departament/05_plans/01_planificacio_territorial/ plans_territorials_nou/territorials_parcials/ptp_metropolita_de_barcelona/index.html (accessed 13 May 2013).

34 Kruis AL, Ställberg B, Jones RC, et al. Primary care COPD patients compared with large pharmaceutically-sponsored COPD studies: an UNLOCK validation study. PLOS ONE 2014;9:e90145. 